\title{
PRICE OPTIMIZATION MODEL FOR PLATFORM'S GOODS AND SERVICES IN MULTI-SIDED MARKETS
}

\author{
Anzhela Ignatyuk', Inna Honcharuk², Bohdan Yakymchuk ${ }^{3}$
}

\begin{abstract}
Purpose. The study is aimed at defining the nature of platforms in multi-sided markets in order to find the price optimization model for platform's goods and services. Methodology. The article used general scientific and special research methods. The generalization of the main methodological approaches to the study of the essence of multi-sided markets, the identification of factors affecting the platform's pricing strategy were based on the methods of dialectics, scientific abstraction, and systemic analysis. The basis of the study of the essence of "platforms" was laid on the use of the following methods: analysis and synthesis, induction and deduction, generalization. Economic and mathematical modeling, scientific abstraction, systemic structural analysis contributed to the development of our own model of the optimal strategy for choosing the price of goods and services by platforms. Findings. The article defines factors that affect the pricing of platform's goods and services. An economic and mathematical model has also been developed to determine an optimal strategy for choosing the price in terms of Nash equilibrium. There have been identified three main factors, which produce the most significant impact on the price of goods and services of platforms: marginal costs; rate of return of another product is being implemented by the platform; elasticity of demand and price. Practical implications. In the conclusions, not only the advantages but also the limitations of the proposed economic and mathematical model have been pointed out, which can be addressed in further studies and implemented into specific living model of economic decisions while price optimization model for platform's goods and services in multi-sided markets. Originality/value. The article is generalizing the previous experience within the niche of price optimization model. Also authors have developed their own economic and mathematical model of the optimal strategy for choosing the price for the platform's products or services, which enabled us to identify its dependence on 3 main factors: marginal costs, rates of profitability of other products sold by the platform, elasticity of demand and price. These results can be overcome in future studies. The results and conclusions have been done by the authors and are totally original.
\end{abstract}

Key words: multi-sided markets, optimization-pricing model, platforms, pricing factors, maximizing profits.

JEL Classification: L11, L16, C50, C61

\section{Introduction}

The service sector is becoming increasingly important the multi-sided markets, trends and inconsistencies of their formation and development being even more relevant in the context of the forward-going information technology. Intermediary services are taking on a dimension by implementing the exchange process. Strengthening of globalization processes of the world economy leads to the interdependence of business entities of different countries and the expansion of international trade, which, in turn, eventuates in the emergence of new intermediaries - platforms.

Platforms not only provide buyers and sellers with the opportunity to interact, increase the efficiency of the exchange process between entities of market relations, minimize transaction costs, expand the product and geographical boundaries of markets, but also transform the market structure, generating a new

\footnotetext{
Corresponding author:

${ }^{1}$ Taras Shevchenko National University of Kyiv, Ukraine.

E-mail: ignatyuk@ukr.net

ORCID: https://orcid.org/0000-0002-9103-6943

ResearcherID: https://www.researchgate.net/profile/Anzhela_Ignatyuk

${ }^{2}$ Taras Shevchenko National University of Kyiv, Ukraine.

E-mail: inna.goncharuk2016@gmail.com

ORCID: https://orcid.org/0000-0002-2129-6037

ResearcherID: https://www.researchgate.net/profile/Inna_Honcharuk3

${ }^{3}$ Taras Shevchenko National University of Kyiv, Ukraine.

E-mail: bogdan.yakymchuk@gmail.com

ResearcherID: https://www.researchgate.net/profile/Bogdan_Yakymchuk
} 
form - a multi-sided market. Such markets as the social media market, advertising, retail, taxi service, and rental housing markets have been subject to transformation due to the constant development of technology. Facebook, Google, Amazon, Airbnb, Uber and others are prominent examples of such platforms.

Despite the fact that the concept of "multi-sided market" has arose recently, this issue, however, has already become the subject of scientific debate among representatives of European and American economic schools. The economic justification of the markets that are formed as a result of the platforms was carried out by the well-known contemporary economists J. Tirole and J. Rochet (2003) in their article "Platform Competition in Two-Sided Markets", where the main subject is the platform, and the term "two-sided market" was used for the first time. In this work the scientists analyzed the essence of two-sided markets, which "are characterized by the presence of two distinct sides whose ultimate benefit stems from interacting through a common platform". Note that although the name of the category "two-sided market" used by J. Tirole and J. Rochet (2003) coincides with the name of the phenomenon, which was studied by D. Gale and L. Shapley (1964), they are different in subjective composition and economic content, so they should not be identified.

The economic value of the studies by J. Tirole and J. Rochet (2006) is that they have identified new key characteristics inherent in two-sided markets by the development of information technologies, in particular, platforms as structure forming entities, as well as their impact on market relations and the economy as a whole.

In the works by J. Tirole and J. Rochet (2006), the platform is a key market participant because it has the role of the so-called intermediary, which combines groups of market participants, each having its own goals, which may be achieved as long as they interact via this platform. One of the main features of such markets is that the price that must be paid for direct access to the platform may differ for each of the groups; however, it is the price discrimination that ensures common welfare. The determination of the access price depends on the degree of difficulty of attracting a group to the platform, i.e. one group of participants can partially or fully subsidize others. Given the price discrimination, the problem of regulating such markets arises, since, according to traditional practice, subsidizing in the market is considered as a monopoly influence on price formation. J. Tirole (2003) recommends the development of specific methods for regulating such markets owing to the fact that price discrimination in multi-sided markets does not reduce, but rather increases the general welfare of all participants. M. Armstrong and J. Wright (2007) were among the first to explore price competition in multi-sided markets. Their main contribution was the introduction of the term "multi-home" and the development of a model for maximizing platform profits in a situation where consumers can simultaneously use competitors' digital networks.

An important element to the study of price methods for platform competition is the publications by the Russian scientists, in particular, A. Shastitko, A. Parshina (2016) and A. Kovalenko (2017). Researchers substantiate the need to improve the mechanism of their state regulation to ensure conditions for the development of competition through the prism of correlation of research results in the field of multi-sided markets, product and geographical boundaries of the market, market entry barriers and power of market participants.

The theoretical analysis of competition in multi-sided markets is provided in the works by I. Ruhmer (2010), where, based on the model by M. Armstrong (2006) (single addressing model), the probability of collusion in the multi-sided market is considered. According to the model developed by the scientist, the growth of external network has two opposite effects: on the one hand, incentives for collusion are growing, but on the other hand, they are decreasing. With increasing asymmetries in indirect positive network effects, the collusion is harder to maintain.

D. Evans and R. Schmalensee (2006) identified the main anti-competitive strategies of firms in multi-sided markets and, using mathematical modeling, proved the inefficiency of using traditional tools to analyze market competition.

B. Jullien (2011), H. Halaburda and J. Yehezkel (2016) supplemented the study of multi-sided markets, considering the behavior of platforms in dynamics. The platform, which occupies a leading position in the market, will always choose safe technology (since the risk of losing market share is quite high), while new or outsider platforms will choose radical technology (the only way to gain market leadership). The main achievement of this study is the substantiation of dynamism and speed of leadership change in multisided markets compared to classical ones, as well as the intensification of price competition between platform firms due to the constant development of innovations. However, these findings are valuable for some types of multi-sided markets, as there are markets where the monopoly maximizes public welfare and the platforms hold leadership positions for a long period.

Despite the large number of publications devoted to the problems of the formation and effective functioning of multi-sided markets, the essence of platforms as key subjects of these markets, the researchers have rather superficially analyzed pricing issues given the novelty of the scientific direction at the current stage, in particular, the criteria for choosing a pricing strategy for goods and services by using platforms.

One of the first studies on platform pricing is the study of a group of scientists led by M. Agrawal (2005). 
The scientists tried to develop a formula for determining the platform's profit when setting optimal prices with the help of the computer simulation method. The mathematical model proposed by scientists provides an estimate of costs based on the transaction costs theory. As a result, several criteria for effective pricing by platform firms have been identified: - the price level for each group of participants, which ensures maximum profit, depends on the level of costs of changing participants in groups (consumers between suppliers and suppliers between consumers)

- the rate of outdated information about market conditions for each group about another.

Analyzing studies of the platform pricing criteria, it is impossible to overlook the work by E. Weyl (2010), which combines the development of the mathematical model with visualization of real situations. In this work, the author develops a platform pricing model, analyzes the influence of factors such as customer loyalty to the services provided by the platform, the elasticity of the tendency to use a digital network at a price. According to the given patterns, this model makes it possible to compare the market power of various groups of platform participants with a view to developing an appropriate pricing policy. Using the example of interaction of a periodical with readers and advertisers, E. Weyl (2010) determines the following pattern: the more regular readers there are, the more profitable for a publication to lower prices for them and raise prices for advertisers, as well as limit the amount of advertisements placed, and vice versa - the smaller the percentage of regular readers is, the more profitable it is to raise prices for them and lower prices for advertisers while increasing the number of advertisements placed.

D. Parker, T. Eisenmann, and M. Van Alstyne (2011) developed several pricing models for platforms. The first of these joint studies concerned the pricing of goods and services offered by the platform, taking into account the following factors: the ability to take advantage of cross-side network effects; user sensitivity to the price and quality of goods and services; production costs. Another work is "Platform Coverage" (2018), which concerns cross-platform interactions and the choice of an appropriate pricing strategy. Depending on the economic connection of the platforms ("complement platforms", "substitute platforms" or unrelated platforms), the authors developed an appropriate pricing strategy. If the platforms provide services that are complementary, then the price should depend on the possibility of a combination of users of these firms. This can be achieved by establishing free access to the new platform, providing additional services or concluding exclusive contracts. If the platforms provide services that are interchangeable, then the pricing strategy should depend on the differentiation of services. If there is no functional connection between them, the possibility of saving on diversity will be minimal, which limits the use of different pricing strategies, since they will not be able to significantly affect the preferences of potential users.

The above mentioned studies became the blueprint for new ones devoted to determining the equilibrium price in multi-sided markets, in particular S. Sato's (2016) "Freemium as optimal menu pricing"; G. Tan and C. Zhou's (2017) "Price competition in multisided markets"; F. Chen and D. Zhu's (2018) "Price strategy and network-size allocation strategy in a twosided monopoly market" and others. For example, in their article, G. Tan, C. Zhou (2017) developed a model of price competition between platforms offering differentiated services in multi-sided markets. Taking into account direct and cross network effects, the authors improved the discrete choice model in order to maximize the utility of each of the groups of participants. In a symmetrical environment with full market coverage, there is a symmetric equilibrium of prices and it is determined for each group of participants according to the following rule: price is equal to costs plus markup due to product differentiation minus subsidies from cross-effects.

\section{Results and discussion}

\subsection{What is a platform?}

Platforms not only transform the economic behavior of business entities and end consumers, complicate economic relations between them, but also serve as a structural element of a new type of market - the multisided market. The platform is not a new phenomenon. The main idea of its emergence is to combine groups of participants in market relations with different needs and interests. Platforms include newspapers, magazines, fairs, hospitals and the like. However, in the context of the development of digital economy, their character is getting more complicated, while their importance is increasing. They not only provide buyers and sellers with the opportunity to interact, but also can reduce the price of goods, speed up the exchange process, and expand the geographical and product boundaries of the market by enhancing positive network effects and increasing returns to scale. In the scientific literature there is no single approach to determining the economic nature of these categories.

J. Tirole and J. Rochet (2003) are considered the founders of studies of modern platforms, because of all the economists they have been among the first to propose a new approach to determining their essence, based on the significance of network effects. The scientists have identified the category of "platform" and "multi-sided market" and defined it as a trading platform that provides for an interaction between end users and tries to keep them "on board", determining the market entry price for each group of participants. The studies of J. Tirole and J. Rochet have been further developed 
in the works by M. Armstrong, D. Evans, J. Parker, A. Kovalenko and others.

For example, D. Evans and R. Schmalensee (2013) note that the platform should be understood as a technology that minimizes transaction costs or creates value, ensures operations that are impossible to implement without this technology. In turn, J. Parker (2016) claims that the platform is a company that provides for "mutually beneficial interactions between third-party manufacturers and consumers. It provides participants with an open infrastructure and sets the rules. The main objective of the platform is to create connections between users and facilitate the exchange of goods or social currency, thereby contributing to the creation of value by all participants". In his writings, Russian researcher A. Kovalenko (2017) adheres to the approach that the platform is "a special type of business model, offers a marketplace for market interaction of several user groups. At the same time, the entire dynamics of the exponential growth of multi-sided platforms is ensured by a double cross network effect".

The French National Digital Council has determined that the platform is a service that acts as an intermediary in accessing information, content, services or products published or provided by third parties. In addition to its technical interface, it organizes and prioritizes content for demonstration and communication with end users.

Researchers of the theory of multi-sided markets today have not reached consensus with regard to the definition of their essence and have proposed various options to designate this phenomenon: "business platform", "digital platform", "online platform", "multisided platform", "platform company". In our opinion, each of them is an interpretation of the same concept and focuses on a specific peculiarity or a feature. From the standpoint of the economics of industry markets and economic theory, the use of the name "platform" is most relevant, since it is comprehensive and helps to analyze this category as a subject of a multi-sided market.

The analysis of scientific economic literature made it possible to group the following approaches to determining the essence of a platform company: a business model, an intermediary, a trading platform, a technological system.

In our opinion, the platform is a company that uses a special resource - a digital network (technology platform) to ensure the interaction between sellers and buyers via the Internet and enhance network effects. Therefore, for the economic analysis of this phenomenon, it is advisable to use the term "platform", which reveals its essence.

Platforms are structure forming entities of multisided markets, since they create the opportunity for sellers and buyers to enter the market, i.e. they create a platform for the emergence of the market.

The main differences between platforms and classical intermediaries are: strong positive network effects, increasing returns to scale, the use of a specific resource - a digital network, the ownership of the goods remains with the manufacturer (or seller), lack of tangible assets (shops, warehouses, bases, etc.), the formation of a new value - databases, price discrimination for various groups of entities and others.

Markets that were formed due to the emergence of platforms were called multi-sided.

A multi-sided market is a set of economic relations between sellers, buyers and intermediaries (platform firms), which are characterized by having positive network effects.

\subsection{Factors influencing on pricing for platform's goods and services}

Price is the main indicator that directly affects the performance of firms. A considerable amount of foreign publications is devoted to the issue of platform pricing; however, the issue of optimal pricing strategy for platform products and services is not fully covered due to the novelty of the scientific direction. Analyzing the scientific literature, we have identified the following factors that determine the pricing strategy of platform companies:

- positive direct and cross network effects;

- price elasticity of demand;

- user sensitivity to price and quality;

- number of product groups;

- platform costs;

- single or multiple addressing;

- innovation;

- number of platforms on the market.

The choice of pricing mechanism also depends on the type of platforms. L. Philistracci classified platforms into transactional and non-transactional ones. Non-transactional platforms charge for advertising revenue and the cost of access to the platform for end users is 0 (such as Google, Facebook, and others). Transaction platforms charge for each successful transaction. Sellers or manufacturers usually include a fee in the price of the item. According to the conditions set by the platform company, entry fees may also be charged. However, this approach is not used in the current context, since the establishment of the platform access fee for entities with the highest price elasticity does not overcome the "chicken and egg problem".

To date, the most effective way to attract and retain an end consumer is to set a zero price for access to the platform, and sometimes even a negative one, where competition between platforms is quite intense (promotions, raffles, additional fees for attracting new users, etc.). For example, the Booking platform has developed a "join friend" incentive system where a participant receives a certain amount of money when joining each new end customer. This tendency is common not only in the hotel services market but also 
in the social networking market (sometimes called as an instant messaging market), search engines and others. All platforms in these markets offer zero-cost access to the market and enhance engagement by establishing additional benefits upon joining.

\subsection{Model}

Based on our research, we have developed an economic and mathematical model for determining the optimal Nash equilibrium strategy for pricing products and services of platforms in multi-sided markets.

Suppose that a platform $X_{1} \in M$ ( $M$ is plurality $L$ platforms) offers $n_{k}^{A}$ products in $k=\overline{1, m^{A}}$ product segments and competes with other platforms in $X \in M$ each of them for different product groups. The market is represented by the plurality $N$ of competing goods, $K=\sum_{k=1}^{m^{X^{I} \in M^{X}}} n_{k}^{X^{I} \in M^{X}}, X^{I} \in M^{X}$ where it represents a common set of goods within a certain common product category (i.e. goods are interchangeable, $\left.\frac{\partial q_{i}^{X_{1}}}{\partial p_{i}^{M \backslash X_{1}}} \geq 0\right)$.

Accordingly, the demand for product $i$ on platform $X_{1}$ will be constantly changing over time $\tau \in T$, depending on the level of royalties (commissions) that the platform and the corresponding adjusted price $p_{i \tau}^{X_{1}}$, the vector of prices for the similar product on other platforms $\left\{P_{i}^{M \backslash X_{1}}\right\}_{\tau}$ and the aggregate supply $\left\{P_{N \backslash i}^{X}: \forall X \in M\right\}_{\tau}$ are required for each transaction:

$$
q_{i \tau}^{X_{1}}=f\left(p_{i \tau}^{X_{1}},\left\{P_{i}^{M \backslash X_{1}}\right\}_{\tau},\left\{Q_{N \backslash i}^{X}: \forall X \in M\right\}_{\tau}\right)
$$

The connections between the components are as follows:

- price increases for similar products, offered by other platform companies $M \backslash X_{1}$, have a positive effect on the sales of this company $X_{1}: \frac{\partial q_{i}^{X_{1}}}{\partial p_{i}^{M \backslash X_{1}}} \geq 0$;

- the rise in prices for goods within the platform $X_{1}$ reduces the demand: $\frac{\partial q_{i}^{X_{1}}}{\partial p_{i}^{X_{1}}}<0$

- the growth in demand for aggregate commodities, placed on the platform $X_{1}$, will affect a gradual decline in prices on the platform itself (royalties), in turn reducing the demand for the platforms $M \backslash X_{1}: \frac{\partial q_{i}^{X_{1}}}{\partial q_{N \backslash i}^{X_{1}}}>0$.

Let the marginal cost of the platform for the placement of product $i$ at the moment $\tau$ be equal $c_{i \tau}^{X_{i}}>0$, and the fixed costs $F^{X_{1}}$ not depend on the time range. A condition for maximizing the discounted continuous flow of earnings $P F_{i}(\tau)$ :

$$
P F^{X_{1}}(\tau)=\int_{0}^{\infty} \pi^{X_{1}}(\tau) e^{-R \tau} \partial \tau,
$$

where $R>0$ is the discount rate.
Then the platform maximizes its own flow if:

$$
P F^{X_{1}}(\tau)=\sum_{i=1}^{K} \int_{0}^{\infty}\left(q_{i}^{X_{1}}(\tau) \cdot\left(p_{i}^{X_{1}}(\tau)-c_{i}^{X_{1}}(\tau)\right) e^{-R \tau} \partial \tau\right)-F^{X_{1}}
$$

Consider the optimal platform strategy for a short period of time $(\tau \rightarrow 0)$ such that the company profits:

$$
P F^{X_{1}}=\sum_{i=1}^{K}\left(q_{i}^{X_{1}} \cdot\left(p_{i}^{X_{1}}-c_{i}^{X_{1}}\right)\right)-F^{X_{1}}=q^{X_{1} T}\left(p^{X_{1}}-c^{X_{1}}\right)-F^{X_{1}},
$$

where

$$
\begin{aligned}
& q^{X_{1}}=\left(q_{1}^{X_{1}}, q_{2}^{X_{1}}, \ldots, q_{K}^{X_{1}}\right), p^{X_{1}}=\left(p_{1}^{X_{1}}, p_{2}^{X_{1}}, \ldots, p_{K}^{X_{1}}\right), \\
& c^{X_{1}}=\left(c_{1}^{X_{1}}, c_{2}^{X_{1}}, \ldots, c_{K}^{X_{1}}\right)
\end{aligned}
$$

are, respectively, demand, price and marginal cost vectors of the platform $X_{1}$.

When all platforms are interoperable, the optimal Nash equilibrium price maximizing strategy is described by

$$
\begin{aligned}
& \overline{p^{X_{1}}}: \overline{P F^{X_{1}}}\left(\overline{p^{X_{1}}}, p_{i}^{M / X_{1}}\right) \geq \overline{P F^{X_{1}}}\left(p^{X_{1}}, p_{i}^{M / X_{1}}\right), \\
& \forall p^{X_{1}} \neq \overline{p^{X_{1}}}
\end{aligned}
$$

This is explained by the strategic involvement of all players in the market when any platform maximizes profit:

$$
\begin{aligned}
& P F^{X_{j}}=\sum_{i=1}^{K}\left(f \left(p_{i}^{X_{j}},\left\{P_{i}^{M / X_{j}}\right\}_{\tau},\right.\right. \\
& \left.\left.\left\{Q_{N \backslash i}^{X}: \forall X \in M\right\}_{\tau}\right) \cdot\left(p_{i}^{X_{j}}-c_{i}^{X_{j}}\right)\right)-F^{X_{j}}
\end{aligned}
$$

where in turn

$$
Q_{N \backslash i}^{X_{j}}=f\left(P^{X_{1}}, P^{X_{2}}, \ldots, P^{X_{L}}\right), X_{j} \in M, J=\overline{1, L}
$$

After a series of transformations, the optimization equation will look like:

$$
0=q_{i}^{X_{j}}+\left(p_{i}^{X_{j}}-c_{i}^{X_{j}}\right) \cdot \frac{\partial q_{i}^{X_{j}}}{\partial p_{i}^{X_{j}}}+\sum_{k \in\{N \backslash i\}}\left(p_{i}^{X_{j}}-C_{i}^{X_{j}}\right) \cdot \frac{\partial q_{k}^{X_{j}}}{\partial p_{i}^{X_{j}}}
$$

Arising from the illustrated above, we have:

$$
\begin{aligned}
& p_{i}^{X_{j}}=c_{i}^{X_{j}}-\sum_{k \in\{N \backslash i\}}\left(p_{i}^{X_{j}}-c_{i}^{X_{j}}\right) \cdot \frac{\partial q_{k}^{X_{j}}}{\partial q_{i}^{X_{j}}}-\frac{q_{i}^{X_{j}}}{\left(\partial q_{i}^{X_{j}} / \partial p_{p_{i}}^{X_{j}}\right)}= \\
& =c_{i}^{X_{j}}-\sum_{k \in\{N \backslash i\}}\left(p_{i}^{X_{j}}-c_{i}^{X_{j}}\right) \cdot \frac{\partial q_{k}^{X_{j}}}{\partial q_{i}^{X_{j}}}-\frac{p_{i}^{X_{j}}}{E_{q_{i} / p_{i}}^{X_{j}}}
\end{aligned}
$$

where $E_{q_{i} p_{i}}^{X_{j}}$ is the price elasticity of demand.

Thus, we get the decomposition of the platform price by the optimal Nash strategy at some point $\tau$ :

$$
p_{i}^{X_{j}}=\frac{C_{i}^{X_{j}}-\sum_{k \in\{N \backslash i\}}\left(p_{i}^{X_{j}}-C_{i}^{X_{j}}\right) \cdot \frac{\partial q_{k}^{X_{j}}}{\partial q_{i}^{X_{j}}}}{\left(1+1 / E_{q_{i} / p_{i}}^{X_{j}}\right)},
$$

Demonstrating the dependence on 3 major factors: - marginal costs $c_{i}^{X_{j}}$;

- rates of profitability of other products of the platform $X_{j}$ :

$$
\sum_{k \in\{N \backslash i\}}\left(p_{i}^{X_{j}}-C_{i}^{X_{j}}\right) \cdot \frac{\partial q_{k}^{X_{j}}}{\partial q_{i}^{X_{j}}} ;
$$

- and price elasticity of demand 


$$
E_{q_{i} / p_{i}}^{X_{j}}=\frac{p_{i}^{X_{j}}}{C_{i}^{X_{j}}-\sum_{k \in\{N i j\}}\left(p_{i}^{X_{j}}-C_{i}^{X_{j}}\right) \cdot \frac{\partial q_{k}^{X_{j}}}{\partial q_{i}^{X_{j}}}-p_{i}^{X_{j}}} .
$$

\section{Conclusion}

This paper deals with the scientific economic literature on the study of the formation and development of multi-sided markets, features of the functioning of platforms, as well as describes the works, dedicated to the platform pricing in multisided markets. Based on the conducted research, we have formulated our own definition of the platform as a company that uses a special resource - digital network (technology platform) to ensure interaction between sellers and buyers through the Internet and enhance network effects. It is also determined that the differences between platforms and classic intermediaries are as follows: strong positive network effects; increasing returns to scale; using a specific resource - a digital network; ownership of the product remains with the manufacturer (or seller); lack of tangible assets (shops, warehouses, bases and etc.); the formation of the new value - databases; price discrimination for different groups of entities and others.

The markets that have been created from the emergence of platforms were called multi-sided. A multi-sided market is a set of economic relationships between sellers, buyers and intermediaries (platform companies), characterized by having positive network effects.

The study of theoretical pricing models, developed by foreign scientists, allowed us to determine the following factors that help to identify the optimal pricing strategy by the firm platform: positive direct and cross network effects; price elasticity of demand; user sensitivity to price and quality; the amount of product groups; platform costs; single or multiple addressing; innovation; number of platforms on the market and others.

Based on our research, we have developed our own economic and mathematical model of the optimal strategy for choosing the price for products or services of the platform, which enabled us to identify its dependence on 3 main factors: marginal costs, rates of profitability of other products sold by the firm-platform, elasticity of demand and price.

Despite the advantages, our model has a number of limitations, in particular: the pricing formula can only be used by platform companies that earn royalties (commission) from each successful buyer-seller agreement, but not adapted to the platforms that receive revenue from advertising or network access fees; there is no consideration of the important factor - multihome. These limitations can be overcome in future studies.

\section{References:}

Agrawal, M., Hariharan, G., Kishore, R., \& Rao, H. (2005). Matching intermediaries for information goods in the presence of direct search: An examination of switching costs and obsolescence of information. Decision Support Systems, 41, 20-36.

Armstrong, M. (2006). Competition in two-sided markets. RAND Journal of Economics, 37(3), 668-691.

Armstrong, M., \& Wright, J. (2007). Two-sided markets, competitive bottlenecks and exclusive contracts. Economic Theory, 32(2). Available at: http://discovery.ucl.ac.uk/14561/1/14561.pdf

Caillaud, B., \& Jullien, B. (2003). Chicken \& Egg: competition among intermediation service providers. RAND Journal of Economics, 34(2), 309-328.

Chen, F., \& Zhu, D. (2018). Price Strategy and Network-Size Allocation Strategy in a Two-Sided Monopoly Market. SSRN. Available at: https://ssrn.com/abstract $=3146878$

Crémer, J., Montjoye, Y.-A., \& Schweitzer, H. (2019) Competition Policy for the digital era. European Commission. Available at: https://ec.europa.eu/competition/publications/reports/kd0419345enn.pdf

Digital business in France: overview (2019). Practical Law. Available at: https://uk.practicallaw.thomsonreuters.com/ 5-618-4887? bhcp=1\&transitionType $=$ Default \&contextData $=($ sc.Default $)$ \&firstPage $=$ true

Dolzenko, R. (2016). Some pricing issues on multisided crowdsourcing platforms. Vestnik NGUEU, Finansy, bukhgalterskiy uchet $i$ analiz, 3, 137-152.

Eisenmann, T., Parker, G., \& Van Alstyne, M. (2011) Platform envelopment. Strategic Management J., 32(12), 1270-1285.

Eisenmann, T., Parker, G., \& Van Alstyne, M. (2006). Strategies for two-sided markets. Harvard Business Review, 84(10), 92-101.

Evans, D., \& Noel, M. (2008). The Analysis of Mergers that involve Multisided Platform Businesses. Journal of Competition Law and Economics, 4(3). Available at: http://michael-noel.com/research/articles/NOEL twosidedmergers.pdf

Evans, D., \& Schmalensee, R. (2013). The Antitrust Analysis of Multi-sided Platform Businesses. The Law School, The University of Chicago. Available at: http://www.law.uchicago.edu/Lawecon/index.html

Evans, P., \& Gawer, A. (2016). The rise of the platform enterprise: a global survey. The Emerging Platform Economy Series, The Center for Global Enterprise, 1, 1-30. Available at: http://thecge.net/wp-content/uploads/2016/01/ PDF-WEB-Platform-Survey_01_12.pdf 
Filistrucchi, L., Klein, T., \& Michielsen, T. (2010). Merger simulation in a two-sided market: The case of the dutch daily newspapers. NET Institute Working Paper, 10-15. Available at: https://pdfs.semanticscholar.org/0491/0248 $6 \mathrm{acb} 18315625357269855065092 \mathrm{c} 8 \mathrm{cc} 4$

Gale, D., \& Shapley, L. (1962). College Admissions and the Stability of Marriage. American Mathematical Monthly, 69(1), 9-15.

Hagiu, A., \& Wright, J. (2013). Do you really want to be an eBay? Harvard Business Review, 91(3). Available at: https://hbr.org/2013/03/do-you-really-want-tobe-an-ebay

Halaburda, H., \& Yehezkel, Y. (2016). The Role of Coordination Biasin Platform Competition. Journal of Economics and Management Strategy, 25, 274-312.

Ignatyuk, A., \& Ignatyuk, V. (2012). Network effects models and their practical application. Visnyk Chernivets'koho torhovel'no-ekonomichnoho instytutu. Chernivtsi: CHTEI KNTEU, 1(45), 405-418.

Jullien, B. (2011). Competition in multi-sided markets: Divide and conquer. American Economic Journal: Microeconomics, 3(4), 186-219.

Kaiser, U., \& Wright, J. (2006). Price Structure in Two-Sided Markets: Evidence the Magazine Industry. International Journal of Industrial Organization, 24, 1-28.

Katz, M., \& Shapiro, C. (1985). Network externalities, competition, and compatibility. The American economic review, 75(3), 424-440.

Kovalenko, A. (2017). A multilateral platform as a value creation network. Manager, 4, 39-42.

Parker, G., Van Alstyne, M., \& Choudaray, P. (2016). Platform revolution: How networked markets are transforming the economy-and how to make them work for you. New York: W. W. Norton.

Rochet, J., \& Tirole, J. (2003). Platform competition in two-sided markets. Journal of the European Economic Association, 1(4), 990-1029.

Rochet, J., \& Tirole, J. (2006). Two Sided Markets: A Progress Report. RAND Journal of Economics, 37(3), $645-667$. Roson, R. (2005). Two-sided markets: A tentative survey. Review of Network Economics, 4(2), 142-160.

Ruhmer, I. (2010). Platform Collusion in Two-Sided Markets, Center for Doctoral Studies in Economics. Mannheim University. Available at: https://www.econstor.eu/bitstream/10419/37258/1/VfS_2010_pid_406.pdf_

Sato, S. (2019). Freemium as optimal menu pricing. International Journal of Industrial Organization, 63, 480-510.

Shastitko, A., \& Parshina, E. (2016). Two-Sided Markets: The Subject Matter Specification. Modern competition, $1,5-18$.

Tan, G., \& Zhou, J. (2017). Price Competition in Multi-Sided Market. SSRN Electronic Journal. Available at: http://ecmandy.people.ust.hk/2018HKUSTIO/Junjie\%20Zhou-SSRN-id3029134.pdf

Weyl, E. (2010). A price theory of multi-sided platforms. Amer. Econom. Rev., 100(4), 1642-1672. 